\title{
Presentation of Ligands on Hydroxylapatite
}

Barbara C. F. Chu and Leslie E. Orgel

The Salk Institute for Biological Studies, P.0. Box 85800,

San Diego, California 92186-5800

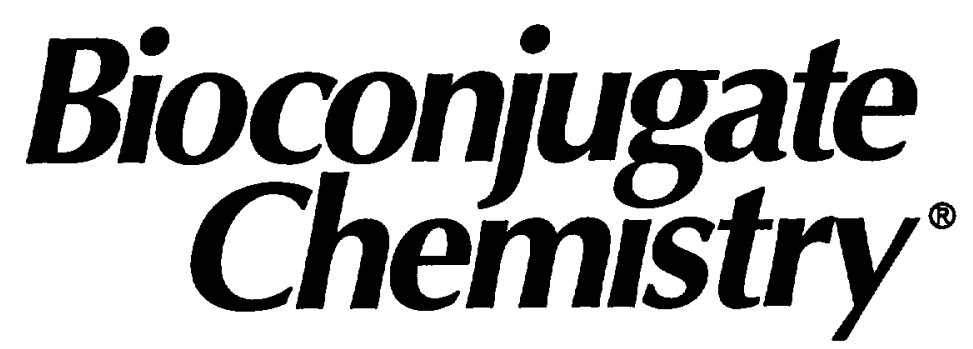

Reprinted from

Volume 8, Number 2, Pages 103-105 


\title{
Presentation of Ligands on Hydroxylapatite
}

\author{
Barbara C. F. Chu and Leslie E. Orgel*
}

The Salk Institute for Biological Studies, P.O. Box 85800, San Diego, California 92186-5800. Received December 17, $1996^{\circ}$

\begin{abstract}
Conjugates of biotin with the decamer of glutamic acid $\left(\mathrm{glu}_{10}\right)$ and the trimer of D,L-2-amino-5phosphonovaleric acid (I) have been synthesized, and it has been shown that they mediate the binding of avidin to hydroxylapatite. In a similar way a conjugate of methotrexate with glu ${ }_{10}$ mediates the binding of dihydrofolate reductase to the mineral. The presentation of ligands on the hydroxylapatite component of bone may find applications in clinical medicine.
\end{abstract}

Peptides containing several aspartic and glutamic acid residues, oligonucleotides, and other polyanions bind strongly but reversibly to hydroxylapatite; this is the basis of hydroxylapatite chromatography $(1,2)$. We have recently found that oligomers of glutamic acid as short as the hexamer bind quantitatively to hydroxylapatite and are not removed by washing with water or a $0.1 \mathrm{M}$ $\mathrm{NaCl}$ solution (3). This suggests that negatively charged polypeptides might be used as linkers to bind ligands to the mineral component of bone with controllable affinity and retention time. In this paper we show that conjugates of biotin and methotrexate with negatively charged peptides may be used to mediate the binding of avidin and dihydrofolate reductase, respectively, to hydroxylapatite.

Glu $\mathrm{u}_{10}$ was gynthesized by the Peptide Biology Laboratory at The Salk Institute. D,L-2-Amino-5-phosphonovaleric acid (I), methotrexate (MTX), chicken liver dihy-

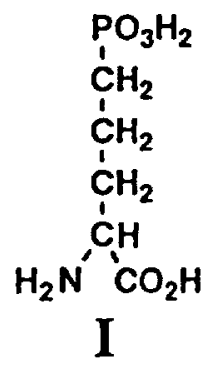

drofolate reductase (DHFR), and $N$-hydroxysuccinimide (N-OH-succ) were obtained from Sigma; 1,1-carbonyldiimidazole (CDI) and dicyclohexylcarbodiimide (DCC) were from Aldrich. Succinimidyl-6-(biotinamido) hexanoate (NHS-LC-Biotin II) was obtained from Pierce, streptavidin from Boehringer, ${ }^{125} \mathrm{I}$-labeled streptavidin from Amersham, and hydroxylapatite (HA) from Bio-Rad.

The biotin derivative of glu $_{10}$ was synthesized by reacting $25 \mathrm{nmol}$ of the oligomer with $190 \mathrm{nmol}$ of NHSLC-Biotin II in $20 \mu \mathrm{L}$ of $0.1 \mathrm{M} \mathrm{NaHCO}_{3}$ buffer at $\mathrm{pH} 8.4$ for $45 \mathrm{~min}$. The product was purified on a $\mathrm{C}_{18}$ column using a $0.1 \%$ TFA/acetonitrile gradient and its identity confirmed by LDMS (calculated for $\mathrm{C}_{66} \mathrm{H}_{97} \mathrm{~N}_{13} \mathrm{O}_{34} \mathrm{~S}+\mathrm{Na}^{+}$ 1670.6; found 1670.7).

* Author to whom correspondence should be addressed [telephone (619) 453-4100, ext 1321; fax (619) 558-7359; e-mail orgel@sc2.salk.com].

Abstract published in Advance ACS Abstracts, February 15, 1997.
The MTX derivative of glu $_{10}$ was synthesized via an $N$-hydroxysuccinimide intermediate (4). A solution (40 $\mu \mathrm{L}$ ) containing $0.05 \mathrm{M}$ MTX, 0.05 M N-OH-succ, and 0.05 $M$ DCC in DMF was allowed to stand at room temperature for $1 \mathrm{~h}$ and then at $2-4{ }^{\circ} \mathrm{C}$ overnight. Ten microliters of the resulting solution was added to 5-25 nmol of $\mathrm{glu}_{10}$ in $30 \mu \mathrm{L}$ of $0.02 \mathrm{M} \mathrm{NaHCO}_{3}$ at $\mathrm{pH}$ 8.2. The reaction mixture was shaken in the dark for $4 \mathrm{~h}$ and then diluted with $70 \mu \mathrm{L}$ of water. Unreacted MTX and salts were removed by shaking the reaction mixture with 10 mg of HA overnight, removing the supernatant, and washing the HA with water. Glu $\mathrm{u}_{10}$ and its MTX conjugate were eluted by shaking the HA with $2 \times 50 \mu \mathrm{L}$ of $0.02 \mathrm{M}$ pyrophosphate for $30 \mathrm{~min}$. The conjugate was purified by HPLC on a $\mathrm{C}_{18}$ column. Its identity was confirmed by LDMS (calculated for $\mathrm{C}_{70} \mathrm{H}_{92} \mathrm{~N}_{18} \mathrm{O}_{35}+\mathrm{H}^{+}$ 1745.6; found 1745.0).

Oligomers of D,L-2-amino-5-phosphonovaleric acid (pvl) were synthesized from the monomer (I) using carbonyldiimidazole (CDI) as a condensing agent (5). A solution of the monomer at $\mathrm{pH} 8(0.05-0.1 \mathrm{M})$ was added to a 3 -fold excess of solid CDI, and the resulting solution was allowed to stand for $6 \mathrm{~h}$ (or overnight). Products ranging from the dimer to the pentamer were identified by paper chromotography ( $n$-PrOH/ $\mathrm{NH}_{3} / \mathrm{H}_{2} \mathrm{O}$ 7:1:2), and samples of the oligomers were eluted from the paper. HPLC of the reaction mixture on an RPC-5 column gave a series of peaks that were assigned to oligomers of known length by cochromatography with the material eluted from paper.

To determine the shortest oligomer that binds to $\mathrm{HA}$, 2-3 $\mu \mathrm{g}$ of the dimer, trimer, tetramer, or pentamer was separately shaken with $10 \mathrm{mg}$ of $\mathrm{HA}$, and any oligomer retained by the $\mathrm{HA}$ was eluted with $\mathrm{K}_{4} \mathrm{P}_{2} \mathrm{O}_{7}$ as described above. HPLC analysis of the supernatant and $\mathrm{K}_{4} \mathrm{P}_{2} \mathrm{O}_{7}$ eluate showed that trimers and longer oligomers of pvl were found only in the eluate and therefore had been bound by the HA. Dimers were not bound to $H A$ and were found in the supernatant fraction.

To obtain the biotin derivative of (pvl) $)_{3}, 6 \mu \mathrm{g}$ of the tripeptide isolated from RPC-5 was first adsorbed to 10 mg of HA. The solid was separated by centrifugation and washed with $\mathrm{H}_{2} \mathrm{O}$ to remove Tris and other components of the HPLC buffer. (Pvl) 3 was then eluted with pyrophosphate as described above. $\left(\mathrm{Pvl}_{3}(5-10 \mu \mathrm{g})\right.$ in $20 \mu \mathrm{L}$ of buffer containing $0.2 \mathrm{M}$ pyrophosphate and $0.2 \mathrm{M}$ $\mathrm{NaHCO}_{3}$ ( $\mathrm{pH} \mathrm{8.4)} \mathrm{was} \mathrm{added} \mathrm{to} 0.1 \mathrm{mg}$ of solid NHS-LC Biotin II. The reaction mixture was then allowed to stand for $1 \mathrm{~h}$ at room temperature. The biotinyl derivative of the tripeptide was purified and isolated using an 
Table 1. Biotin-Mediated Binding of Streptavidin to Hydroxylapatite

\begin{tabular}{lcc}
\hline & $\begin{array}{c}\%\left[{ }^{125} \mathrm{I}\right] \text { streptavidin } \\
\text { in supernatant }\end{array}$ & $\begin{array}{c}\%\left[{ }^{125} \mathrm{I}\right] \text { streptavidin } \\
\text { on hydroxylapatite }\end{array}$ \\
\hline glu $_{10}$ & 97 & 3 \\
pvl $_{3}$ & 97 & 3 \\
biotin-glu & & 75 \\
biotin-pvl & 25 & 68
\end{tabular}

RPC-5 column. Its identity was confirmed by ESMS (calculated for $\mathrm{C}_{31} \mathrm{H}_{57} \mathrm{~N}_{6} \mathrm{O}_{16} \mathrm{P}_{3} \mathrm{~S}-\mathrm{H}$ 893.2; found 893).

To recruit streptavidin to $\mathrm{HA}, 1 \mathrm{nmol}$ of biotin-glu $\mathrm{u}_{10}$ or biotin-(pvl) $)_{3}$ was first shaken with $1 \mathrm{mg}$ of $\mathrm{HA}$ in 20 $\mu \mathrm{L}$ of $0.01 \mathrm{M}$ Tris-ClO ${ }_{4}$ for $6 \mathrm{~h}$ (or overnight) at room temperature. The supernatant was removed by centrifugation, and the HA was washed with $100 \mu \mathrm{L}$ of water. A solution of $0.1 \mathrm{nmol}$ of ${ }^{125}$ I-labeled streptavidin (25 000$50000 \mathrm{cpm}$ ) in $100 \mu \mathrm{L}$ of buffer containing $1 \mathrm{M} \mathrm{KCl}$ and $0.01 \mathrm{M}$ phosphate at $\mathrm{pH} 6.5$ was added to the $\mathrm{HA}$ and shaken for $45 \mathrm{~min}$. The supernatant was removed by centrifugation and the $\mathrm{HA}$ washed several times with 200 $\mu \mathrm{L}$ of $\mathrm{H}_{2} \mathrm{O}$. The amounts of radioactivity found in the supernatant, wash, and HA fractions were then measured (see Table 1). In control experiments, biotin-glu $u_{10}$ was replaced by glu $_{10}$ and biotin-(pvl $)_{3}$ was replaced by (pvl) $)_{3}$. When a peptide bound to the HA was ligated to biotin about $70 \%$ of the streptavidin was recruited to the HA and 25-30\% remained in the supernatant (Table 1). In the control experiments no more than $5 \%$ of the streptavidin was bound to the HA. Clearly the preadsorption of biotin conjugates of negatively charged polypeptides greatly enhances the adsorption of avidin to HA.

To recruit dihydrofolate reductase to $\mathrm{HA}, 1 \mathrm{nmol}$ of MTX-glu 10 was adsorbed to $\mathrm{HA}$ as described above for biotin-glu 10 . DHFR $(0.52 \mathrm{nmol})$ in $200 \mu \mathrm{L}$ of buffer containing $0.1 \mathrm{M}$ ammonium sulfate, $0.01 \mathrm{M}$ potassium phosphate, at $\mathrm{pH} 6.4$, and $5 \%$ glycerol was added to the HA and shaken for $45 \mathrm{~min}$. The HA was separated from the supernatant, washed with $100 \mu \mathrm{L}$ of water, and then eluted twice with $20 \mu \mathrm{L}$ of $0.02 \mathrm{M} \mathrm{K}_{4} \mathrm{P}_{2} \mathrm{O}_{7}$. In control experiments the MTX-glu ${ }_{10}$ was replaced by glu $_{10}$. The supernatant, the washes, and the pyrophosphate eluate were analyzed on a $6 \%$ acrylamide SDS gel using Coomassie Blue to visualize DHFR. Figure 1 shows that in the control experiments with glu $\mathrm{u}_{10}$ more than $75 \%$ of the DHFR was found in the supernatant (Figure 1, lane 1) and only a small amount in the pyrophosphate eluate (Figure 1, lane 3). In experiments involving MTX-glu ${ }_{10}$ more than $75 \%$ of the DHFR was found in the pyrophosphate eluate (Figure 1, lane 6) and very little in the supernatant (Figure 1, lane 4). Preadsorption of MTX-glu 10 $_{10}$, therefore, greatly increases the amount of DHFR that binds to HA.

The above results show that conjugates of various ligands with anionic polypeptides adsorbed noncovalently on hydroxylapatite could be used as supports for affinity chromatography. More importantly, HA presents special opportunities in a related context, because it is the main mineral component of bone. The surface of bone is freely accessible to molecules in the extracellular fluid even if they are as large as proteins (6). The bisphosphonates, small molecules carrying four negative charges, have been used extensively to attach technetium to hydroxylapatite for bone scintigraphy (7). One example of the recruitment of an anticancer drug, methotrexate, to bone using a bisphosphonate has been reported (8). We believe that anionic polypeptides may prove particularly convenient as carriers of ligands to bone and may sometimes have advantages over the bisphosphonates.

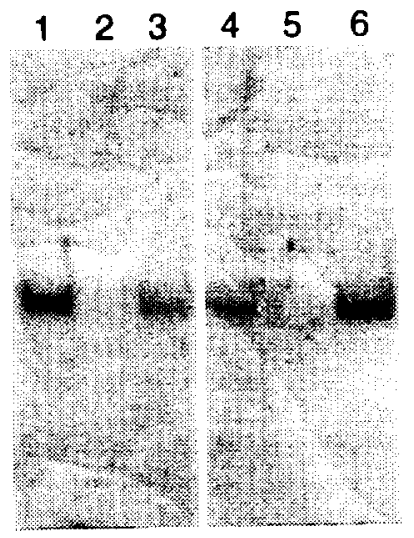

Figure 1. Coomassie Blue stained SDS gel showing DHFR in the supernatant (lanes 1 and 4), the wash (lanes 2 and 5), or the pyrophosphate eluate (lanes 3 and 6) after shaking a solution of the enzyme with glu $10^{-}$-bound hydroxylapatite (HA) (lanes 1-3) or with MTX-glu 10 -bound HA (lanes 4-6). One nanomole of glu $_{10}$ or MTX-glu 10 was shaken with $1 \mathrm{mg}$ of HA for $6 \mathrm{~h}$. Excess peptide was removed by washing. The glu $10^{-}$or MTX-glu 10 -bound HA was then shaken with $0.52 \mathrm{nmol}$ of DHFR for $45 \mathrm{~min}$. The supernatant was removed by centrifugation and the HA washed with $100 \mu \mathrm{L}$ of water. The glu ${ }_{10}$ and MTX-glu 10 together with any bound DHFR were eluted from the HA by shaking with $2 \times 50 \mu \mathrm{L}$ of pyrophosphate solution for $30 \mathrm{~min}$.

The mechanism of action of bisphosphonates on bone resorption is not fully understood, but it seems clear that it is not entirely a matter of adsorption to hydroxylapatite. The properties of osteoblasts are profoundly affected by submicromolar concentrations of bisphosphonates, suggesting that they attach to receptors, possibly pyrophosphate receptors, on the cell surface (9). The structures of polypeptides are completely unrelated to that of inorganic pyrophosphate, so by using them as carriers it should be possible to dissociate the direct effects of adsorption to HA from the indirect effects due to interaction with extracellular receptors on osteoblasts (or osteoclasts).

Polypeptides are uniquely convenient as carriers, because effective automated methods are already available for their synthesis, and the use of combinatorial peptide libraries is well-established. The strength of adsorption of the carriers could easily be controlled via their length, while more or less degradable carriers could be obtained by varying the ratio of $D$ - to L-residues. In the special case of a peptide ligand, the ligand and the anionic carrier could be assembled in a single solid-phase peptide synthesis. Presentation of ligands on HA that interact directly with receptors on osteoblasts or osteoclasts, or which recruit proteins to bone, may find applications in medicine.

\section{ACKNOWLEDGMENT}

This work was supported by Grant GM33023 from the National Institute for Allergy and Infectious Diseases and Grant NAWG-1660 from the National Aeronautics and Space Administration. We are grateful to Prof. A. Michael Parfitt (University of Arkansas for Medical Sciences) for much helpful advice. We thank Aubrey R. Hill, Jr., for technical assistance and Sylvia Bailey for manuscript preparation.

\section{LITERATURE CITED}

(1) Bernardi, G. (1971) Chromatography of Proteins on Hydroxyapatite. In Methods in Enzymology. Vol. XXII. Enzyme purification and related techniques (W. B. Jakoby, Ed.) pp 325-339, Academic Press, New York. 
(2) Bernardi, G. (1973) Chromatography of Proteins on $\mathrm{Hy}$ droxyapatite. In Methods in Enzymology. Vol. XXVII. Enzyme Structure, Part D (C. H. W. Hirs and S. N. Timasheff, Eds.) pp 471-479, Academic Press, New York.

(3) Chu, B. C. F., Hill, A. R., Jr., and Orgel, L. E. (1996) Unpublished results.

(4) Kulkarni, P. N., Huntley Blair, A., and Chose, T. I. (1981) Covalent binding of methotrexate to immunoglobulins and the effect of antibody-linked drug on tumor growth in vivo. Cancer Res. 41, 2700-2706.

(5) Ehler, K. W., and Orgel, L. E. (1976) $N, N^{\prime}$-carbonyldiimidazole-induced peptide formation in aqueous solution. Biochim. Biophys. Acta 434, 233-243.

(6) Doty, S. B., Robinson, R. A., and Schofield, B. (1976) Morphology of Bone and Histochemical Staining Character- istics of Bone Cells. In Handbook of Physiology. Section 7: Endocrinology (G. D. Aurbach, Ed.) pp 3-23, American Physiological Society, Washington, DC.

(7) Fogelman, I., Maisey, M. N., and Clarke, S. E. M. (1994) An Atlas of Clinical Nuclear Medicine, pp 1-110, Mosby, St. Louis, MO.

(8) Hosain, F., Spencer, R. P., Couthon, H. M., and Stuirtz, G. L. (1994) Targeted delivery of antineoplastic agent to bone: biodistribution studies of technetium-99m-labeled gem-bisphosphonate conjugate of methotrexate. J. Nuclear Med. 37, 105-107.

(9) Fleisch, H. (1995) Bisphosphonates in Bone Disease, pp 4754, Parthenon, New York.

BC970015V 